Methods: This is a prospective observational multi-centre study of visual involvement attributable to GCA. Demographic, disease features and treatment information was collected on all patients with new or relapsing GCA with or without visua symptoms (VS) or SL.SL was defined as symptomatic loss of acuity, field of vision or diplopia ascribable to ischaemic complications of GCA. Patients with transient VS were not considered to have SL. Analyses were performed using chi-squared and rank sum tests.

Results: Patients were predominantly female (274/388) and Caucasian; 3 nonCaucasian(Asian British, Black/Afro-Caribbean and Turkish).VS were present in $135 / 388$ patients (35\%) from 19 UK sites. Of patients with VS, these were transient or intermittent SL $(n=9,7 \%)$, diplopia ( $n=33,24 \%)$, blurred vision $(n=17,13 \%)$, flashing lights $(n=4,3 \%)$ and eye pain $(n=7,5 \%)$. Transient or permanent loss of acuity occurred in 92 patients (48 anterior ischaemic optic neuropathy [AION], 6 central retinal artery occlusion [CRAO],1 posterior ischaemic optic neuropathy, all attributed to GCA);1 hemispheric retinal vein occlusion, 1 branch retinal artery occlusion, 1 peri-papillary haemorrhage, 1 vitelliform dystrophy macula. 8 had oculomotor nerve palsies(NP)(1 bilateral 3rd,1 bilateral 6th and 6 unilateral 3rd or 6th $N P)$. Patients with VS were older than those without(mean $\pm S D$ age $75.9 \pm 9.3$ and $73.5 \pm 8.5$ respectively, $p<0.001)$. Patients with $V S$ had less headaches $(p=0.012)$ and scalp tenderness $(p=0.05)$ but more frequently tongue claudication $(p=0.014)$, shorter symptom duration $(3.9 \pm 5.5$ days, $p=0.001)$, lower CRP although not statistically significant $(p=0.059)$, were less likely to meet ACR criteria and to improve than those without VS $(p<0.001)$. No association was found with comorbidities or deprivation index.SL in $54(40 \%)$ patients was due to AION or CRAO. Transient CRAO or AION was described in 17 and 30/47 (64\%) had permanent SL (data missing from 7 patients). Patients with AION/CRAO were older (80.9 \pm 6.7 years) than those without AION/CRAO $(73.3 \pm 8.7$ years, $p<0.001)$. They had shorter symptom duration $(4.2 \pm 7.0$ days, $p=0.024)$, less likely to improve than those without AION/CRAO $(p<0.001)$, less likely to have headaches $(p<0.001)$ or polymyalgic symptoms $(p=0.002)$, and more likely to have jaw claudication $(p=0.043)$ and hypertension $(p=0.002)$. Only 7 had diplopia on presentation. 5 patients experienced AION as manifestation of recrudescing disease.

Conclusions: VS often leading to SL in GCA requires urgent management. Patients with VS were older, without 'typical symptoms' such as headache and polymyalgia but more likely to have ischaemic symptoms such as jaw and tongue pain and hypertension. Recognition of VS associated features should be embodied in public and professional awareness programs to prevent permanent $S L$ in GCA.

Disclosure of Interest: None declared

DOI: 10.1136/annrheumdis-2018-eular.3081

\section{FRI0495 BEHCET'S SYNDROME IN NEW YORK AND AMSTERDAM: EVOLUTION FROM PROBABLE BEHÇET'S TO ISG CRITERIA POSITIVE BEHÇET'S}

F. Kerstens $^{1,2}$, F. Turkstra ${ }^{1}$, C.J. Swearingen ${ }^{2}$, Y. Yazici ${ }^{2} .{ }^{1}$ Amsterdam Rheumatology and immunology Center, Reade, Amsterdam, Netherlands; ${ }^{2} \mathrm{NYU}$ Hospital for Joint Diseases, New York City, USA

Background: Behçet's syndrome (BS) is an auto-inflammatory vasculitis, most common in countries along the ancient Silk Road. Classification of BS most often is done with the International Study Group criteria (ISG criteria) ${ }^{1}$. ISG criteria positivity for BS is reached when a patient has recurrent oral ulceration and any two of the following symptoms: recurrent genital ulceration, uveitis, skin lesions and pathergy positivity. However, many other manifestations are reported ${ }^{1}$. Differences in clinical presentation can complicate classification of the diagnosis, especially in areas where the disease is low in prevalence. Thus, some patients are classified as "probable BS". In some of these cases patients developed additional symptoms over time and met the ISG criteria in a later stage.

Objectives: To describe characteristics of patients presenting with a probable diagnosis of BS in Amsterdam and New York and to study if patients who eventually met the ISG criteria differ from those who did not.

Methods: We included consecutive patients classified as possible BS to our outpatient clinics in New York and Amsterdam. Patients fulfilling ISG criteria at enrollment were excluded, as well as patients in whom an alternative diagnosis was made at enrollment. Baseline data were evaluated retrospectively and patients were divided into two groups: those developing ISG positive (ISG +or "true") BS during follow up and those who did not meet ISG criteria after follow-up (ISG-). Turkey, Asia, Middle and Far Eastern countries, Arabic countries and Northern Africa were considered endemic areas; Italian, Greek, Hispanic, Portugese, African-American and Caucasian patients were considered not from endemic areas. Statistical analysis was performed using SPSS, with Chi-square tests or Fisher's exact tests for categorical data and independent sample t-tests for numerical data.

Results: 189 patients were included, of whom 20 were from Amsterdam. During follow up, 71 patients $(37.6 \%)$ could be classified as "true" Behçet's syndrome after a mean period of 9.4 years ( \pm 8.3 years) after onset of symptoms. Age, gender, ethnicity, duration of symptoms at enrollment, duration of follow up as well as RAPID3 and almost all clinical manifestations at baseline were comparable for both groups. Labial ulcers and skin manifestations at enrollment were more frequently reported. Genital ulcers as a group was not significantly associated with developing "true" Behçets, nor were specific skin manifestations such as eryth ema nodosum. We also considered HLA-B*51, pathergy, erythrocyte sedimentation rate and C-reactive protein, but due to a large amount of missing data, we were unable to draw any significant conclusions for these variables.

\begin{tabular}{|c|c|c|c|c|}
\hline Characteristics & $\begin{array}{l}\text { All patients } \\
(n=189)\end{array}$ & $\begin{array}{l}\text { ISG + } \\
(n=71)\end{array}$ & $\begin{array}{l}\text { ISG - } \\
(n=118)\end{array}$ & P-value \\
\hline Age years (SD) & $34.3(13.7)$ & $34.1(13.4)$ & $34.5(14.0)$ & ns \\
\hline Male n (\%) & $46(24.3)$ & $13(18.3)$ & $33(28.0)$ & ns \\
\hline $\begin{array}{l}\text { Duration of follow up } \\
\text { years (SD) }\end{array}$ & $3.2(2.4)$ & $3.3(2.5)$ & $3.1(2.4)$ & ns \\
\hline Ethnicity: endemic area $n(\%)$ & $43(22.8)$ & $14(19.7)$ & $29(24.6)$ & ns \\
\hline RAPID3 mean score (SD) & $9.8(6.8)$ & $9.6(6.9)$ & $9.9(6.7)$ & ns \\
\hline $\begin{array}{l}\text { Duration of symptoms } \\
\text { years (SD) }\end{array}$ & $7.3(7.8)$ & $7.7(7.9)$ & $7.0(7.8)$ & ns \\
\hline Oral ulcers n (\%) & $174(92.1)$ & $66(93.0)$ & $108(91.5)$ & ns \\
\hline Genital ulcers n (\%) & $108(57.1)$ & $47(66.2)$ & $61(51.7)$ & ns \\
\hline - Labia & $63(33.3)$ & $31(43.7)$ & $32(27.1)$ & 0.019 \\
\hline Skin disease $\mathrm{n}(\%)$ & $58(30.7)$ & $31(43.7)$ & $27(22.9)$ & 0.003 \\
\hline Eye disease $\mathrm{n}(\%)$ & $33(17.5)$ & $17(23.9)$ & $15(12.7)$ & ns \\
\hline Deep venous thrombosis $n(\%)$ & $4(2.1)$ & $2(2.8)$ & $2(1.7)$ & ns \\
\hline Thrombophlebitis $n(\%)$ & $5(2.6)$ & $2(2.8)$ & $3(2.5)$ & ns \\
\hline Central nervous system n (\%) & $22(11.6)$ & $6(8.5)$ & $16(13.6)$ & ns \\
\hline Vascular disease $n(\%)$ & $7(3.7)$ & $1(1.4)$ & $6(5.1)$ & ns \\
\hline Pulmonary disease $n(\%)$ & $3(1.6)$ & $0(0)$ & $3(2.5)$ & ns \\
\hline Arthritis $n(\%)$ & $35(18.6)$ & $16(22.5)$ & $19(16.1)$ & ns \\
\hline Gastrointestinal disease n (\%) & $40(21.2)$ & $14(19.7)$ & $26(22.0)$ & ns \\
\hline Headache $n(\%)$ & $12(6.3)$ & $5(7.0)$ & $7(5.9)$ & ns \\
\hline Epididymitis $n$ (\% of males) & $3(6.5)$ & $0(0)$ & $3(9.1)$ & ns \\
\hline
\end{tabular}

Figure 1 Baseline data from all patients who were classified as probable Behçet's syndrome at enrollment

Conclusions: About a third of patients classified as probable Behçet's syndrome at enrollment develop new manifestations over time. Thus, they can be reclassified as ISG positive ("true") BS. Based on our data, presence of skin manifestations and labial ulcers at enrollment was significantly higher in the group eventually developing a ISG criteria positive BS.

\section{REFERENCE:}

[1] Criteria for diagnosis of Behcet's disease. International Study Group for Behcet's Disease. Lancet 1990;335(8697):1078-80.

Disclosure of Interest: F. Kerstens Grant/research support from: Stichting Jan van Breemen Grant, F. Turkstra: None declared, C. Swearingen: None declared, Y. Yazici: None declared

DOI: 10.1136/annrheumdis-2018-eular.7069

\section{FRI0496 POLYARTERITIS NODOSA: OVER 20 YEARS' CLINICAL EXPERIENCE}

H.E. Sönmez ${ }^{1}$, B. Armağann ${ }^{2}$, G. Ayan ${ }^{3}$, K. Barut ${ }^{4}$, E.D. Batu ${ }^{1}$, A. Erden² S. Uğurlu ${ }^{3}$, Y. Bilginer ${ }^{1}$, Ö. Kasapçopur ${ }^{4}$, Ö. Karadağ ${ }^{2}$, S.A. Bilgen ${ }^{2}$, H. Özdoğan ${ }^{3}$, S. Özen ${ }^{1} .{ }^{1}$ Department of Peditarics, Division of Rheumatology; ${ }^{2}$ Hacettepe University Faculty of Medicine, Ankara; ${ }^{3}$ Cerrahpasa Medical School, Istanbul University, istanbul, Turkey, ${ }^{4}$ Department of Peditarics, Division of Rheumatology, Cerrahpasa Medical School, Istanbul University, İstanbul, Turkey

Background: Polyarteritis nodosa (PAN) is a necrotizing vasculitis of predominantly medium size vessels.

Objectives: The present study aimed to summarise the characteristics of PAN patients, and also analyse the trend of decreasing PAN frequency in the last 25 years, in Turkey

Methods: Paediatric and adult PAN patients followed up in Hacettepe University and Istanbul University Cerrahpasa Faculty of Medicine between 1990 and 2015 were included. The demographics, clinical findings and outcomes were evaluated retrospectively.

Results: One hundred thirty-three patients, including 66 children, were enrolled in the study. The mean follow-up duration was $13^{2-27}$ years. Among 133 patients $86(64.7 \%)$ had fever, $108(81.2 \%)$ had skin involvement, $54(40.6 \%)$ had renal involvement, $43(32.3 \%)$ had neurological involvement, $32(24.1 \%)$ had gastrointestinal involvement, $10(7.5 \%)$ had cardiac involvement, $6(4.5 \%)$ had pulmonary involvement. The median (minimum-maximum) leukocyte count, erythrocyte sedimentation rate and C-reactive protein levels at the time of diagnosis were 10400 $(6100-32000) / \mathrm{mm}^{3}, 58(2-132) \mathrm{mm} / \mathrm{h}$ and $5.22(0-46) \mathrm{mg} / \mathrm{dL}$, respectively. All patients were ANCA negative. Hepatitis serology was analysed in 121 patients and found positive in 13 of them. MEFV mutations were screened among 65 patients, 24 of them had mutations in at least one allele. Myalgia and skin involvement were significantly more frequent in children whereas neurologic involvement 